\title{
Determination of recoverable wind energy for electricity generation using wind energy conversion system in Tunisia
}

\author{
W. Zghal ${ }^{1, *}$, G. Kantchev ${ }^{1}$, H. Kchaou ${ }^{1}$ \\ ${ }^{1}$ Laboratory of Electromechanical Systems, National Engineering School of Sfax, B.P. W3038, Sfax, TUNISIA \\ "Corresponding Author: e-mail address: zghal_wissem@yahoo.fr, Tel +21697750882
}

\begin{abstract}
Utilization of renewable energy source, essentially the wind energy, has been growing rapidly in the whole world due to environmental pollution, consumption of the limited fossil fuels and global warming. Moreover, wind resource determination is a fundamental step in planning a wind energy project and exhaustive knowledge of the wind characteristic at a site of installation is needed to estimate the performance of a wind energy conversion system. The current paper presents an investigation of the wind power potential using real wind data for five sites in Tunisia: Jendouba, Bizerte, Sfax, Gafsa and Jarzis. The Weibull distribution functions and the Betz theory are applied to describe the wind speed distribution and to determinate the wind power density for these sites. Also, mathematical models are used to calculate the recoverable wind power and the wind energy produced by a wind turbine. According to the power calculations done for the five sites, annual mean power density based on Weibull function is $63.591 \mathrm{~W} / \mathrm{m}^{2}$ in June in Gafsa and in May and June in Jarzis whereas the minimum average value is obtained in Jendouba as $6.521 \mathrm{~W} / \mathrm{m}^{2}$ in October. In addition, a study of the produced wind energy by three different types of wind turbine is elaborated. The results confirm that the Jarzis site presents the better wind energy potential for the utilization. Therefore, it is the most favorable site for the wind installations in the five studied sites.
\end{abstract}

Keywords: determination, wind energy potential, wind speed, wind power density, Weibull and Betz theories

\section{Introduction}

Our developed societies became very excessive in energy. However, sources of energy used now cause many problems. This important increasing need for energy, the global environmental concerns and the rapid depletion of fossil fuel resources on a worldwide basis have necessitated an urgent search for alternative energy sources to supply the present day demands. Therefore, in a durable development perspective, to provide to the present and futures needs of the world society in energy the renewable energies not only constitute an energizing alternative but a choice of society. The utilization of renewable energies has proved to be a mature, reliable and efficient technology for electricity production.

Wind power is becoming the fastest growing renewable energy source in the world. The strong growth in wind power capacity is attributable to the promotion of models of renewable energy sources, energy supply security, fuel diversity concerns, ecological awareness and economic reasons. By the end of 2008, global installed wind power capacity reached 121,188MW and an annual output of approximately $260 \mathrm{TWh}$. At present, wind generated electricity contributes more than $1.5 \%$ to global electricity consumption, and five countries meet more than 6\% of their electricity demand with wind energy (Seyit and Onder, 2010). Moreover, wind energy systems are being considered as promising power generating sources due to their availability and the topological advantages in power generation. In this context and since 1980, Tunisia has formulated its national strategy in the field of new and renewable sources of energy as an integral part of its global energy strategy. Indeed, the first wind power station of electricity production was created in 2000 in Sidi Daoud, in the northeast of the country. It is a power station with the capacity of 20MW. The Tunisian Company of Electricity and Gas (STEG) intends to accomplish an extension project of this wind station to increase its capacity to $53.6 \mathrm{MW}$, which corresponds to $1.5 \%$ of the total power production. The national objective is to reach $100 \mathrm{MW}$ by 2009 (Amar et al, 2008). For an excellent utilization of the wind energy, it is indispensable to determine characteristic and the exploitable quantity of this energy for the implantation site of the wind turbine. 
In the literature, authors (Fyrippis et al., 2010; Amar et al, 2008; Gokcek et al., 2007; Elamouri et al., 2008) use the Weibull and Rayleigh probability density functions for the specification of the wind distribution and the determination of the wind energy potential. Indeed, the paper of Fyrippis et al. (2010) presents an investigation of the wind power potential of Koronos village, a remote location in the northeastern part of Naxos Island, Greece, using real wind data by a measurement mast. The obtained wind characteristics were statistically analyzed using the Weibull and Rayleigh distribution functions. Amar et al. (2008) have statistically analyzed the wind energy potential of the Sidi Daoud site (Tunisia): Weibull and Rayleigh parameters at a height of $30 \mathrm{~m}$ have been estimated and used to describe the distribution and behavior of annual wind speeds and their frequencies at site. For Gokcek et al. (2007), wind characteristics and wind energy potential were analyzed taking into account the wind data measured as hourly time series in the Marmara Region, Turkey. The wind data used in this study were taken from Electrical Power Resources Survey and Development Administration for the year 2004. Weibull and Rayleigh probability density functions of the location are calculated in the light of observed data and Weibull shape parameter $\mathrm{k}$ and scale parameter $\mathrm{c}$ are found. The main objective of Elamouri et al.'s (2008) is to constitute a database for the users of the wind power; this study is elaborated for 17 synoptic sites distributed on all the territory of Tunisia. From the meteorological data provided by the Meteorology National Institute (INM), two statistical methods (meteorological and Weibull) are presented to evaluate the wind speed characteristics and the wind power potential at a height of $10 \mathrm{~m}$.

In our study, we exploit the technique of Weibull but we introduce the Betz theory for a better determination of the wind potential characteristics and to be able to find out the wind power produced by a wind turbine.

\section{Recoverable wind energy}

To appraise the wind power characteristics of a specific site, various methods and techniques have been reported in the literature. In this paper, the evaluation of the recoverable wind energy is based on Betz and Weibull theories and on the meteorological data of the site.

\subsection{Betz theory}

The energy supplied by wind is a kinetic energy; it depends on the mass and velocity of the air volume. Considering a surface S device recovery of this energy and assuming that the wind speed is identical at each point of this surface. Therefore, the wind energy is the recoverable energy of the air that crosses the surface $\mathrm{S}$, the associated power is therefore:

$$
\mathrm{P}_{\mathrm{w}}=\frac{1}{2} \cdot \rho \cdot \mathrm{S} \cdot \mathrm{V}^{3}
$$

$\rho \approx 1.225 \mathrm{~kg} / \mathrm{m}^{3}$, in the normal conditions of temperature and pressure at sea level.

In practice, a wind turbine deflects the wind before it reaches the area swept by the rotor. A wind turbine will never recover the total energy supplied by wind. When the wind's kinetic energy is converted into mechanical energy by the rotor, the wind is slowed by it, the wind speed upstream the rotor is always higher than downstream where the existence of a power coefficient $\mathrm{C}_{\mathrm{p}}$ obviously inferior to one. The power coefficient $C_{p}$ has been introduced by the Betz theory. This coefficient characterizes the level of output of a wind turbine. One can define it as the following report:

$\mathrm{C}_{\mathrm{p}}=\frac{\text { available mechanical power on the wind turbine axis }}{\text { available wind power }}$.

The Betz theory indicates, that for the ideal wind turbine, one recovers in maximum $59 \%$ of the wind energy, what means that $\mathrm{C}_{\mathrm{p} \max }$ (theoretical) is equal to 0.59 (16/27). For a wind turbine (merchandised), this coefficient is the order of 0.3 to 0.4 . Accordingly, one introduces the power coefficient in the calculation of the wind power:

$$
\mathrm{P}_{\mathrm{t}}=\frac{1}{2} \cdot \mathrm{C}_{\mathrm{p}} \cdot \rho \cdot \mathrm{S} \cdot \mathrm{V}^{3} .
$$

\subsection{Wind distribution analysis: Method of Weibull}

The main objective of this study is the assessment of the wind energy in a specific region using the Weibull function. The Weibull technique is the most used model to describe the wind speed distribution. The probability distribution function is given by the following expression (Fyrippis et al, 2010; Amar et al., 2008; Gokcek et al 2007; Elamouri and Amar, 2008; Elamouri et al., 2011; Ucar and Balo, 2009):

$$
f(\mathrm{~V})=\frac{\mathrm{k}}{\mathrm{c}} \cdot\left(\frac{\mathrm{v}}{\mathrm{c}}\right)^{\mathrm{k}-1} \cdot \exp \left[-\left(\frac{\mathrm{v}}{\mathrm{c}}\right)^{\mathrm{k}}\right],
$$

From this function, one can identify the wind potential and one can find out parameters of Weibull (c, $\mathrm{k}$ ) for the different sites. These parameters serve to the determination of other features of the wind energy. The characteristic wind speeds $\left(\mathrm{V}_{\mathrm{m}} \cdot \mathrm{V}_{\mathrm{E}}\right.$. and $\left.\mathrm{V}_{\mathrm{F}}\right)$ are functions of the two Weibull parameters (F.Ben Amar et al, 2008).

The average wind speed of the site, $\mathrm{V}_{\mathrm{m}}$, is expressed by: 


$$
\mathrm{V}_{\mathrm{m}}=\mathrm{c} \cdot \Gamma\left(1+\frac{1}{\mathrm{k}}\right),
$$

with $\Gamma$ is the gamma function definite by:

$$
\Gamma(\mathrm{x})=\int_{0}^{+\infty} \mathrm{t}^{\mathrm{x}-1} \cdot \mathrm{e}^{-\mathrm{t}} \cdot \mathrm{dt} .
$$

The energizing wind speed, $V_{E}$, is expressed by:

$$
\mathrm{V}_{\mathrm{E}}=\mathrm{c} \cdot\left(1+\frac{2}{\mathrm{k}}\right)^{\frac{1}{\mathrm{k}}} .
$$

The frequent wind speed, $V_{F}$, is given by:

$$
\mathrm{V}_{\mathrm{F}}=\mathrm{c} \cdot\left(1-\frac{1}{\mathrm{k}}\right)^{\frac{1}{\mathrm{k}}}
$$

Besides, based on the Weibull probability density function, the theoretical wind power can be expressed as follow:

$$
\mathrm{P}_{\mathrm{wt}}=\frac{1}{2} \cdot \rho \cdot \mathrm{S} \cdot\left(1+3 \cdot \mathrm{I}^{2}\right) \cdot \mathrm{c}^{3} \cdot \Gamma\left(1+\frac{3}{\mathrm{k}}\right),
$$

with I: is the turbulence intensity (generally equal to 0.2 at $10 \mathrm{~m}$ ).

As a result, taking account of Betz theory limitations, the theoretical recoverable wind power is represented by this relation:

$$
\mathrm{P}_{\mathrm{wrt}}=\mathrm{C}_{\mathrm{p}} \cdot \mathrm{P}_{\mathrm{wt}}
$$

\subsection{Variation of wind characteristics according to the installation height}

It is certain that the height of the wind turbine installation presents a big effect on the produced energy. Therefore, the adjustment of the wind profile for the height must be taken in consideration. The wind speed, for a determined height, is expressed as follows:

$$
\frac{\mathrm{v}}{\mathrm{v}_{\text {ref }}}=\left(\frac{\mathrm{z}}{\mathrm{z}_{\mathrm{ref}}}\right)^{\alpha} .
$$

In the same way the available energy is specified by this expression:

$$
\frac{\mathrm{E}}{\mathrm{E}_{\mathrm{ref}}}=\left(\frac{\mathrm{E}}{\mathrm{Z}_{\mathrm{ref}}}\right)^{3 \cdot \alpha} \text {. }
$$

Generally the value of $\alpha$ varies between 0.1 and 0.4 according to the nature of the installation site and its roughness.

Besides, the applied data recovery and the wind energy evaluation for different heights present an excellent advantage to the determination of Weibull distribution. Indeed, if one fix Weibull parameters to a reference height $\left(Z_{\text {ref }}\right)$ then the parameters $\mathrm{c}(Z)$ and $\mathrm{k}(\mathrm{Z})$ are joined to $\mathrm{c}\left(\mathrm{Z}_{\mathrm{ref}}\right)$ and $\mathrm{k}\left(\mathrm{Z}_{\mathrm{ref}}\right)$ by the following relations (F. Ben Amar et al, 2008):

$$
c(Z)=c\left(Z_{\text {ref }}\right) \cdot\left(\frac{Z}{Z_{\text {ref }}}\right)^{n},
$$

and

$$
\mathrm{k}(\mathrm{Z})=\frac{\mathrm{k}\left(\mathrm{Z}_{\mathrm{ref}}\right) \cdot\left(1-0.088 \cdot \operatorname{Ln}\left(\frac{\mathrm{Z}_{\mathrm{ref}}}{10}\right)\right)}{1-0.088 \cdot \operatorname{Ln}\left(\frac{\mathrm{Z}}{10}\right)}
$$

where $\mathrm{n}$ is a scalar that can be determined by this equation:

$$
\mathrm{n}=\frac{0.37-0.088 \cdot \operatorname{Ln}\left(\mathrm{c}_{\mathrm{ref}}\right)}{1-0.088 \cdot \operatorname{Ln}\left(\frac{\mathrm{Z}_{\mathrm{ref}}}{10}\right)} .
$$




\section{Yearly average power generated by a wind turbine}

As one already presented the wind power cannot be totally recovered. The wind power produced, $\mathrm{P}_{\mathrm{wr}}$, is generally deduced from the wind power using the power coefficient $C_{p}$. Therefore, it is necessary to determine this coefficient.

The power coefficient, $C_{p}$, is a non-linear function of the tip speed-ratio $\lambda$ and the pitch angle $\beta$. The tip speed-ratio depends on the wind velocity and the rotation speed of the turbine:

$$
\lambda=\frac{\mathrm{R} \cdot \Omega}{\mathrm{V}} .
$$

Numerical approximations have been developed to calculate the power coefficient, for given values of $\lambda$ and $\beta$. At this point, the following approximation is used (J. G. Slootweg et al, 2003; Jemaa Brahmi et al, 2009):

$$
C_{p}(\lambda, \beta)=0.73 \cdot\left(\frac{151}{\lambda_{i}}-0.58 \cdot \beta-0.002 \cdot \beta^{2.14}-13.2\right) \cdot e^{-18.4 / \lambda_{i}}
$$

Therefore, the recoverable wind power generated by a wind turbine is determined as follows:

$$
\mathrm{P}_{\mathrm{wr}}=\mathrm{C}_{\mathrm{p}}(\lambda, \beta) \cdot \mathrm{P}_{\mathrm{wt}} .
$$

As well, for a wind turbine the recoverable yearly energy is calculated by the following expression:

$$
\mathrm{E}_{\mathrm{wr}}=8.76 \cdot \mathrm{P}_{\mathrm{wr}} .
$$

In fact, the curve of progress of the wind turbine power according to the wind speed (Figure 1) includes four zones:

- Zone «A», where the wind turbine doesn't produce a current: $P_{w r}=0$;

- Zone «B», in which power is a function of the wind speed;

- Zone «C», where the rotation speed of the turbine is maintained constant by a regulation device: the power produced remains equal to $P_{n}$;

- Zone «D», in which the safety system of working wind turbine stops the rotation of the turbine and the transfer of the energy.

Therefore, the already presented models are applied only to determine the power produced by the wind turbine in the zone B.

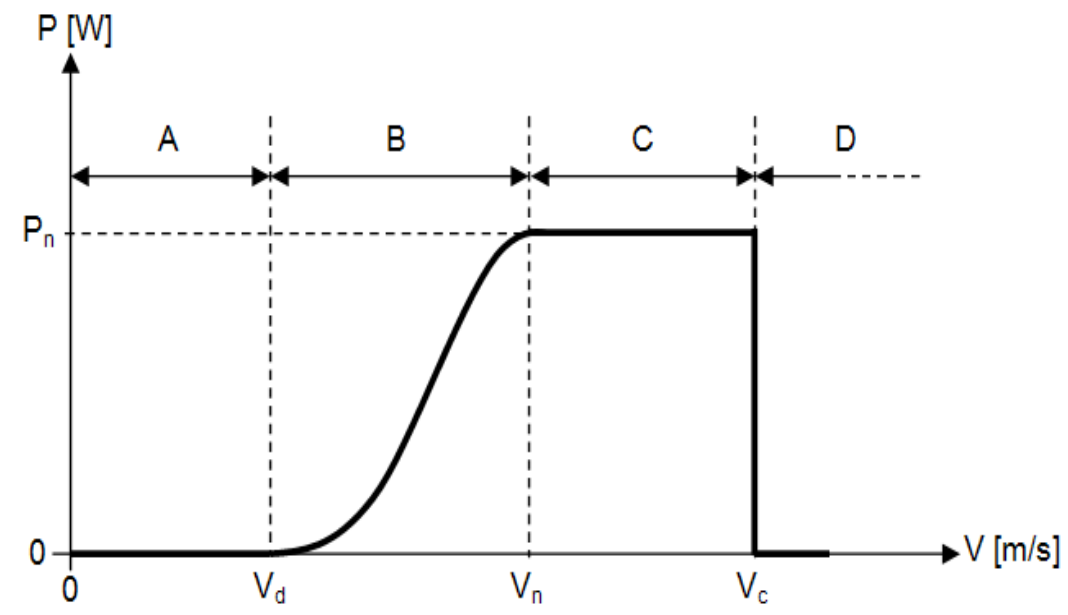

Figure 1. Power output characteristic of a wind turbine.

\section{Results and discussion}

As previously mentioned, the study objective is to determinate the recoverable wind energy that can be used for electricity generation using wind energy conversion system. As a case study, this method is applied to analyze the characteristics of wind power for five sites in Tunisia. Table 1 shows the geographical localization of the five studied sites. 
Table 1. Geographical characteristics of the five studied sites

\begin{tabular}{|l|c|c|c|c|c|}
\hline \multicolumn{1}{|c|}{ Site } & Jendouba & Bizerte & Sfax & Gafsa & Jarzis \\
\hline Latitude & $36.5^{\circ} \mathrm{N}$ & $37.3^{\circ} \mathrm{N}$ & $34.7^{\circ} \mathrm{N}$ & $34.4^{\circ} \mathrm{N}$ & $33.5^{\circ} \mathrm{N}$ \\
\hline Longitude & $8.8^{\circ} \mathrm{E}$ & $9.8^{\circ} \mathrm{E}$ & $10.7^{\circ} \mathrm{E}$ & $8.8^{\circ} \mathrm{E}$ & $11.1^{\circ} \mathrm{E}$ \\
\hline
\end{tabular}

\subsection{Wind energy characteristics}

The mentioned above method will be used for this study. Therefore, Table 2 shows the average monthly wind speeds and power densities $\boldsymbol{P}$ (wind power per unit area) for the five selected locations at $12 \mathrm{~m}$ heights.

Table 2. Average monthly wind speed and power density for the respective sites at height $12 \mathrm{~m}$

\begin{tabular}{|l|c|c|c|c|c|c|c|c|c|c|}
\hline \multicolumn{1}{|c|}{ Site } & \multicolumn{2}{|c|}{ Jendouba } & \multicolumn{2}{c|}{ Bizerte } & \multicolumn{2}{c|}{ Sfax } & \multicolumn{2}{c|}{ Gafsa } & \multicolumn{2}{c|}{ Jarzis } \\
\hline Month & $\begin{array}{c}\mathbf{V}_{\mathbf{m}} \\
{[\mathbf{m} / \mathbf{s}]}\end{array}$ & $\begin{array}{c}\boldsymbol{P} \\
{\left[\mathbf{W} / \mathbf{m}^{2}\right]}\end{array}$ & $\begin{array}{c}\mathbf{V}_{\mathbf{m}} \\
{[\mathbf{m} / \mathbf{s}]}\end{array}$ & $\begin{array}{c}\boldsymbol{P} \\
{\left[\mathbf{W} / \mathbf{m}^{2}\right]}\end{array}$ & $\begin{array}{c}\mathbf{V}_{\mathbf{m}} \\
{[\mathbf{m} / \mathbf{s}]}\end{array}$ & $\begin{array}{c}\boldsymbol{P} \\
{\left[\mathbf{W} / \mathbf{m}^{2}\right]}\end{array}$ & $\begin{array}{c}\mathbf{V}_{\mathbf{m}} \\
{[\mathbf{m} / \mathbf{s}]}\end{array}$ & $\begin{array}{c}\boldsymbol{P} \\
{\left[\mathbf{W} / \mathbf{m}^{2}\right]}\end{array}$ & $\begin{array}{c}\mathbf{V}_{\mathbf{m}} \\
{[\mathbf{m} / \mathbf{s}]}\end{array}$ & $\begin{array}{c}\boldsymbol{P} \\
{\left[\mathbf{W} / \mathbf{m}^{2}\right]}\end{array}$ \\
\hline January & 2.5 & 9.57 & 3.8 & 33.60 & 3.3 & 22.011 & 3.2 & 20.07 & 4.3 & 48.698 \\
\hline February & 2.7 & 12.055 & 4.4 & 52.175 & 3.5 & 26.260 & 3.5 & 26.26 & 4.4 & 52.175 \\
\hline March & 2.8 & 13.445 & 4.4 & 52.175 & 3.8 & 33.609 & 4.1 & 42.214 & 4.6 & 59.618 \\
\hline April & 2.8 & 13.445 & 4.5 & 55.814 & 3.9 & 36.332 & 4.3 & 48.698 & 4.5 & 55.814 \\
\hline May & 2.8 & 13.445 & 4.3 & 48.698 & 3.8 & 33.609 & 4.5 & 55.814 & 4.7 & 63.591 \\
\hline June & 3 & 16.537 & 4.6 & 59.618 & 3.9 & 36.332 & 4.7 & 63.591 & 4.7 & 63.591 \\
\hline July & 3 & 16.537 & 4.6 & 59.618 & 3.5 & 26.26 & 4.1 & 42.214 & 4.1 & 42.214 \\
\hline August & 2.8 & 13.445 & 4.1 & 42.214 & 3.2 & 20.07 & 3.7 & 31.024 & 4.2 & 45.378 \\
\hline September & 2.6 & 10.765 & 4 & 39.2 & 3.5 & 26.26 & 3.7 & 31.024 & 4.1 & 42.214 \\
\hline October & 2.2 & 6.521 & 3.6 & 28.576 & 3.1 & 18.246 & 3.4 & 24.073 & 4.1 & 42.214 \\
\hline November & 2.5 & 9.570 & 3.7 & 31.024 & 3.3 & 22.011 & 3.2 & 20.07 & 4.1 & 42.214 \\
\hline December & 2.6 & 10.765 & 3.9 & 36.332 & 3.5 & 26.26 & 3.1 & 18.246 & 4.3 & 48.698 \\
\hline
\end{tabular}

These data are recovered from meteorological station collections, for the case of Sfax and Jarzis, whereas for the other sites, they are extracted from the illustrated data by the NASA in (RETScreen International). The maximum average power density occurred as $63.591 \mathrm{~W} / \mathrm{m}^{2}$ in June in Gafsa and in May and June in Jarzis whereas the minimum average value is obtained in Jendouba as $6.521 \mathrm{~W} / \mathrm{m}^{2}$ in October. In the same way, Figure 2 shows the variation of the monthly average wind speeds together with the power densities for the selected five sites at $12 \mathrm{~m}$ height. It can be seen that similar changing trends is given by the two plots. This resemblance of variation, in the different sites, is illustrated by formulas shown in the previous part.

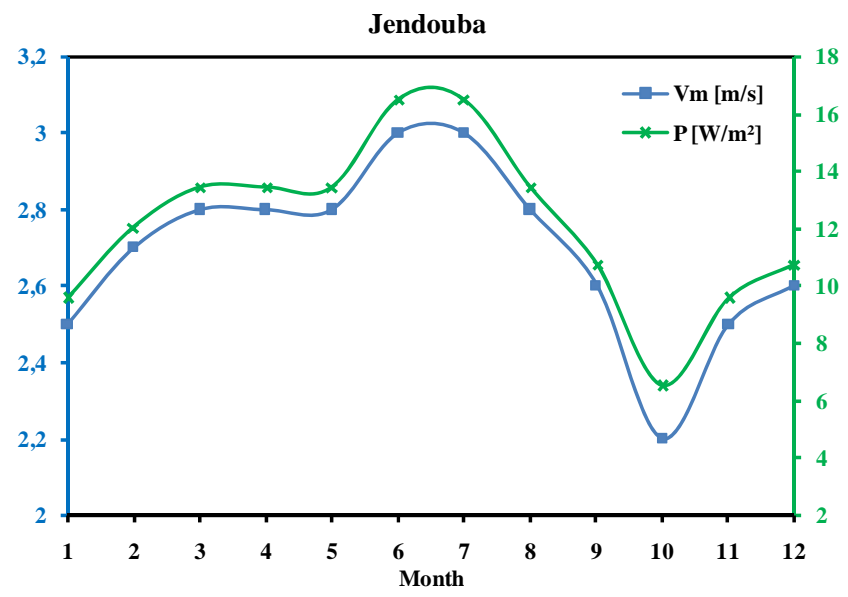

a)

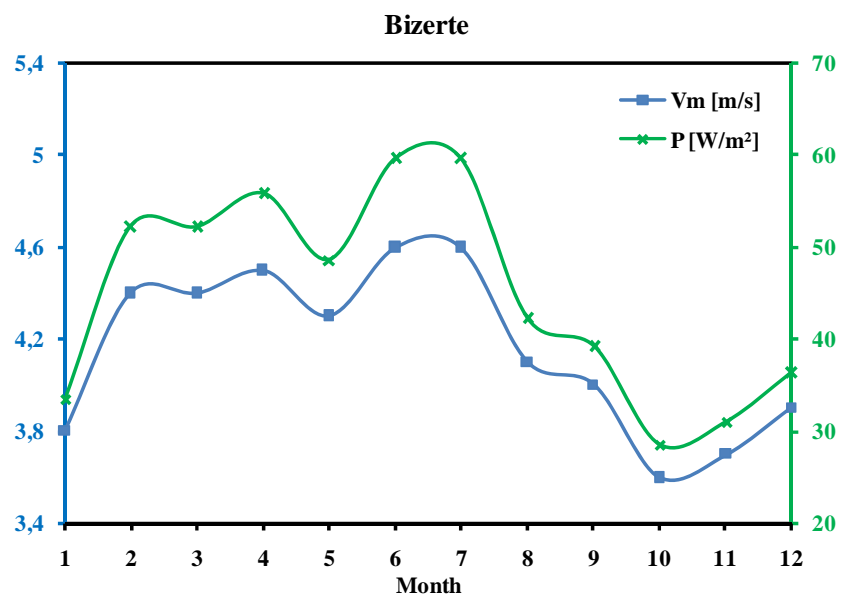

b)

Figure 2. Monthly variation of the average wind speeds (with point) and the power density (with $\times$ ) for a) Jendouba, b) Bizerte 


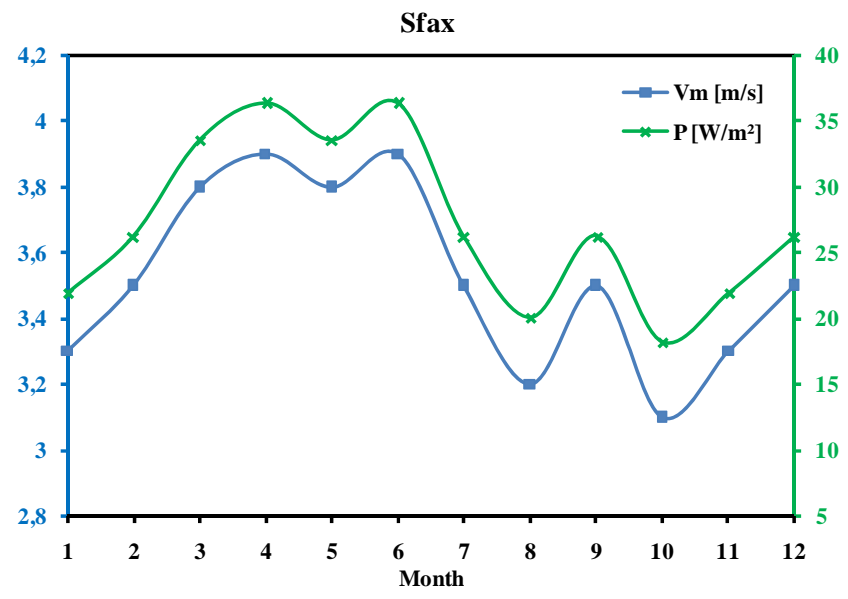

c)

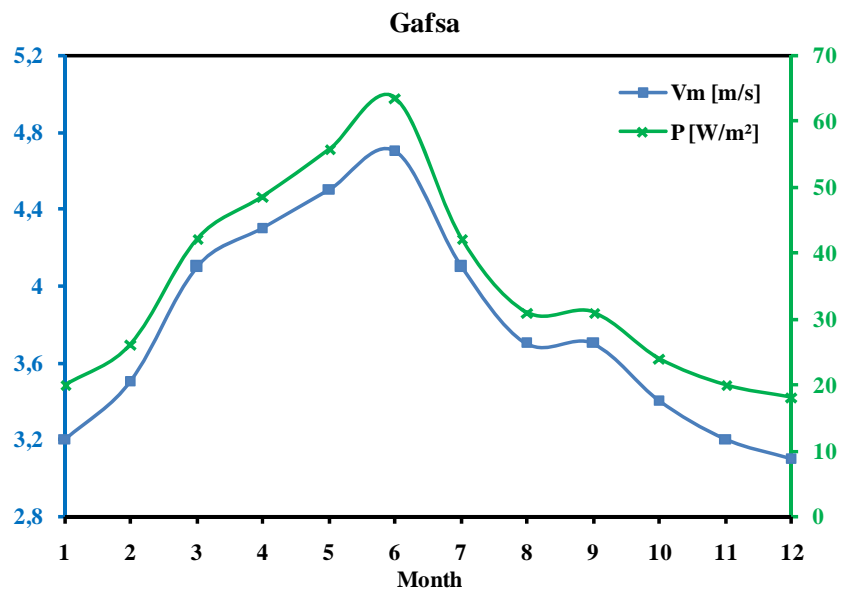

d)

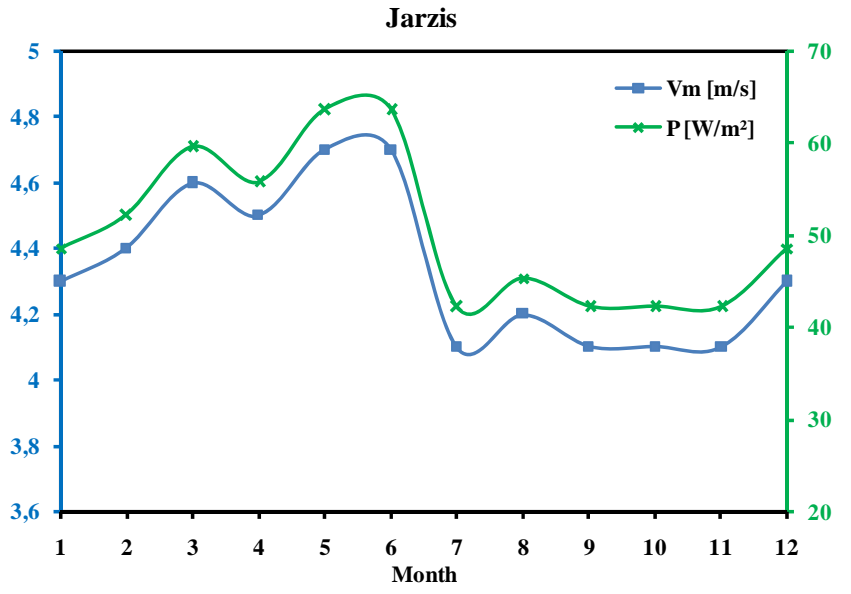

e)

Figure 2 (cont'd.). Monthly variation of the average wind speeds (with point) and the power density (with $\times$ ) for c) Sfax, d) Gafsa and e) Jarzis.

From Table 2 and the Figure 2, we note that the average wind speed varies from a site to another one and some sites are better than other: Jarzis presents the steadiest and biggest wind energy potential; therefore the wind installations will be more profitable in this site. Moreover, as we explained in the previous paragraph, the wind characteristics of a site depend on the height of the installation. Besides the power is proportionally bound to the wind speed therefore the variation of this speed according to the height will produce a variation of the recovered wind power and the power produced by a wind turbine. Figure 3 presents the variation of the wind speed according to the height for the different studied sites.

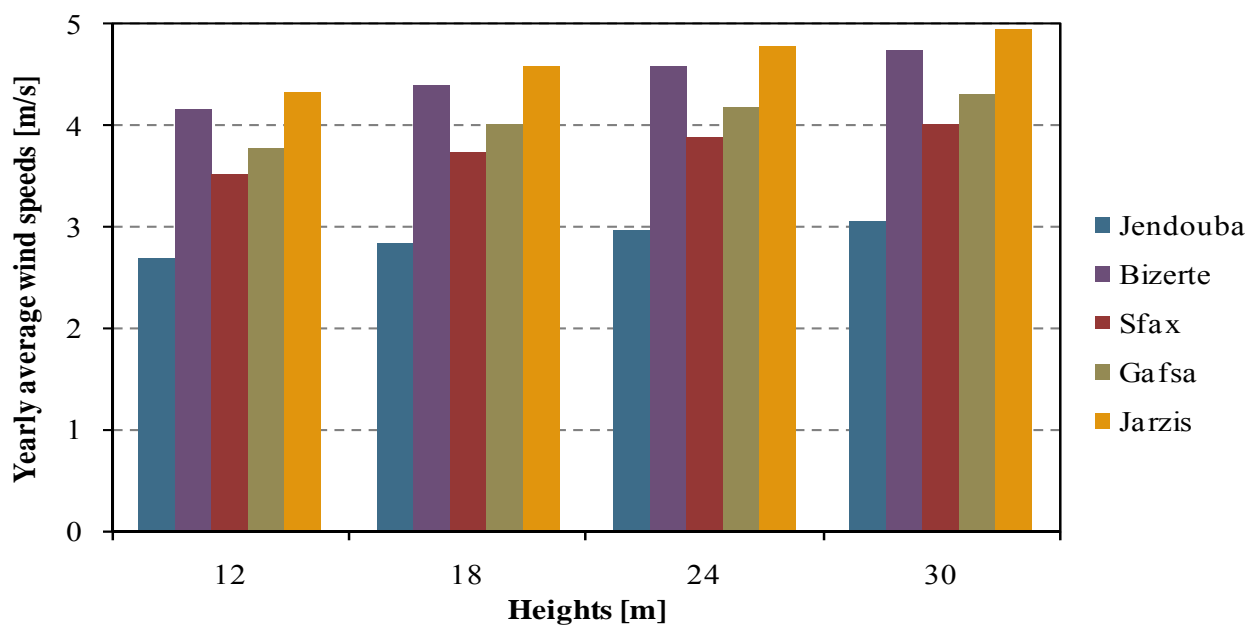

Figure 3. Variation of the yearly average wind speeds with different heights for the five sites 
We note that yearly average wind speeds progress while increasing the height. For example, in Jarzis, this speed passes 4.2 to 5 $\mathrm{m} / \mathrm{s}$ to heights 12 and $30 \mathrm{~m}$ respectively. This evolution can influence the quantity of energy produced by a wind turbine.

\subsection{Wind energy produced}

In this part, a study of the produced wind energy by three different types of wind turbine is elaborated to validate and to complete the already found results. Characteristics of the three types of wind turbine are regrouped in Table 3.

Table 3. Characteristics of the selected wind turbines

\begin{tabular}{|c|c|c|c|}
\hline Characteristics & Type 1 & Type 2 & Type 3 \\
\hline Rated power $\mathbf{P}_{\mathbf{n}}(\mathbf{k W})$ & 1 & 3 & 5 \\
\hline Diameter $\mathbf{( m )}$ & 2.7 & 4.5 & 6.4 \\
\hline Cut-in wind speed $\mathbf{V}_{\mathbf{d}} \mathbf{( m / s )}$ & 2.5 & 2.5 & 2.5 \\
\hline Nominal wind speed $\mathbf{V}_{\mathbf{n}} \mathbf{( m / s )}$ & 9 & 10 & 10 \\
\hline Cut-off wind speed $\left.\mathbf{V}_{\mathbf{c}} \mathbf{( m} / \mathbf{s}\right)$ & 15 & 15 & 15 \\
\hline
\end{tabular}

For the five studied sites, we determined the yearly power produced by every type. Table 4, present the found results. It is clear that the produced power increases when the wind turbine is bigger: it is obvious since the model of calculation of the wind power depends on the wind turbine characteristics.

Table 4. Annual wind power produced by the selected wind turbine for the five sites

\begin{tabular}{|c|c|c|c|}
\hline Wind Turbine & Type 1 & Type 2 & Type 3 \\
\hline Site & $\mathbf{P}_{\mathbf{w r}}[\mathbf{k W} / \mathbf{y e a r}]$ & $\mathbf{P}_{\mathbf{w r}}[\mathbf{k W} /$ year] & $\mathbf{P}_{\mathbf{w r}}[\mathbf{k W}$ /year] \\
\hline Jendouba & 7.817 & 21.715 & 43.923 \\
\hline Bizerte & 30.174 & 83.818 & 169.54 \\
\hline Sfax & 18.334 & 50.928 & 103.013 \\
\hline Gafsa & 23.744 & 65.955 & 133.409 \\
\hline Jarzis & 33.991 & 94.418 & 190.982 \\
\hline
\end{tabular}

We note, for the three types of wind, that the Jarzis site presents the biggest wind power produced whereas the Jendouba site has the smallest values. These results are in agreement with consequences shown in the previous paragraph.

In the same way, we presented, in the different sites, the yearly variation of the wind energy produced by these three types of wind turbine. We could reach, in May in Jarzis, $490 \mathrm{kWh}$ as wind energy produced by a small wind turbine that its nominal power doesn't pass $5 \mathrm{~kW}$. Also, these curves, Figure 4, confirm that the Jarzis site presents the better wind potential. Therefore, it is the most favorable site for the wind installations in the five studied sites.

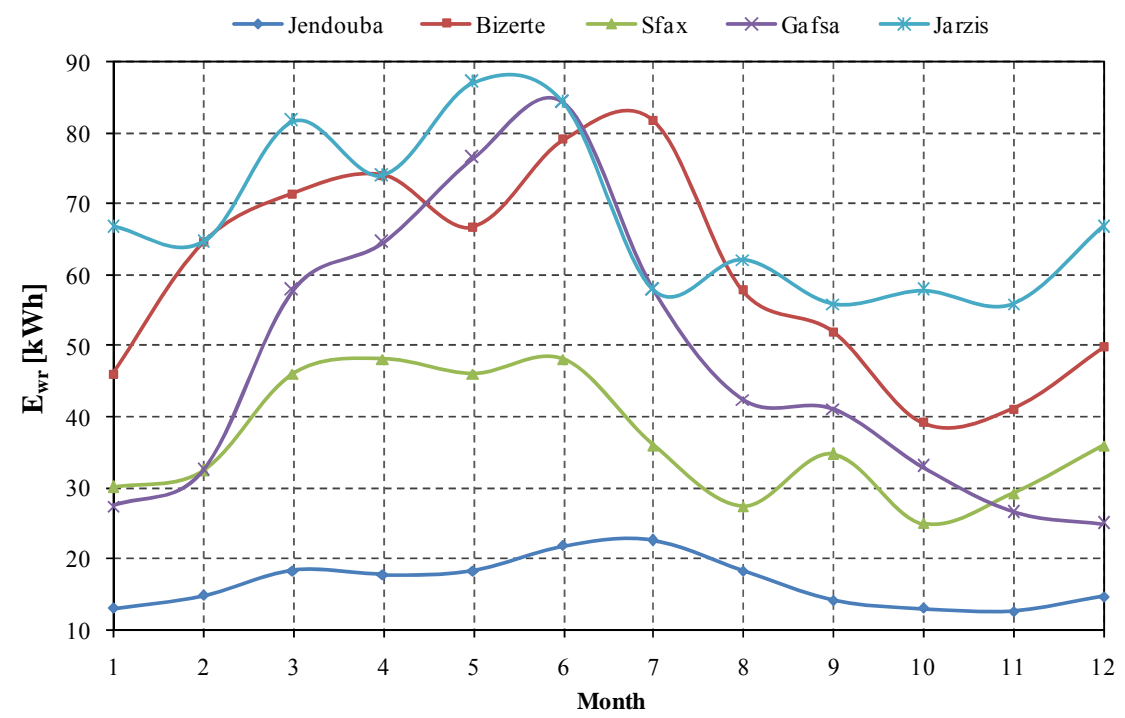

a)

Figure 4. Yearly variation of the wind energy produced by wind turbines in the different sites a) Type 1 


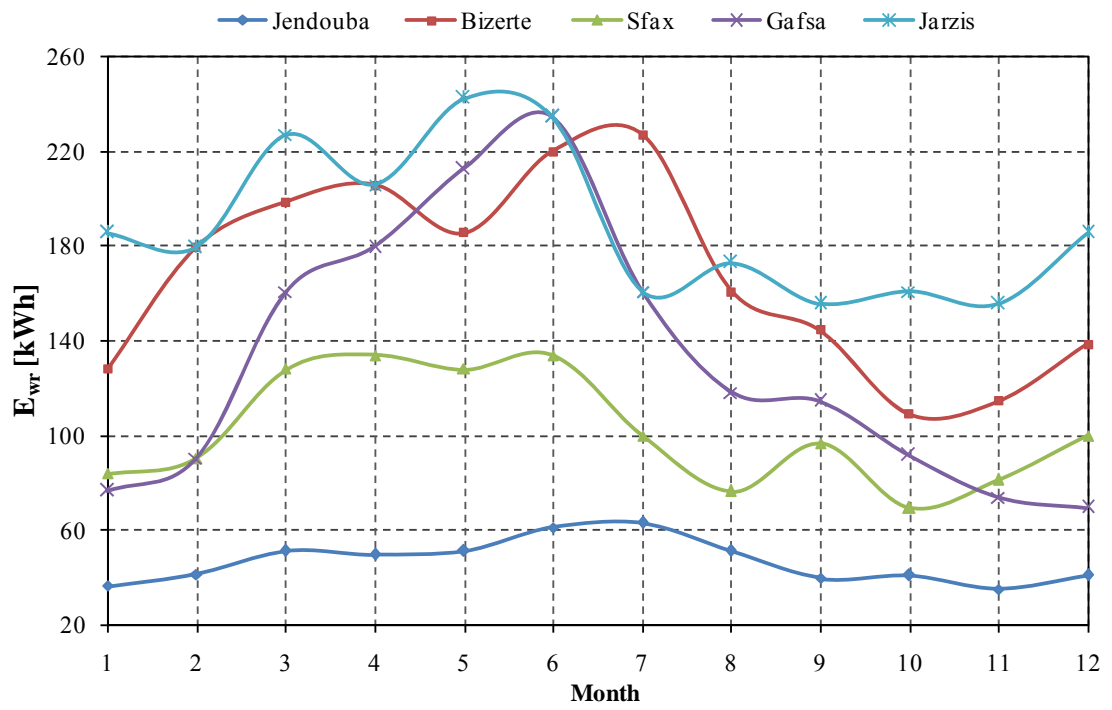

b)

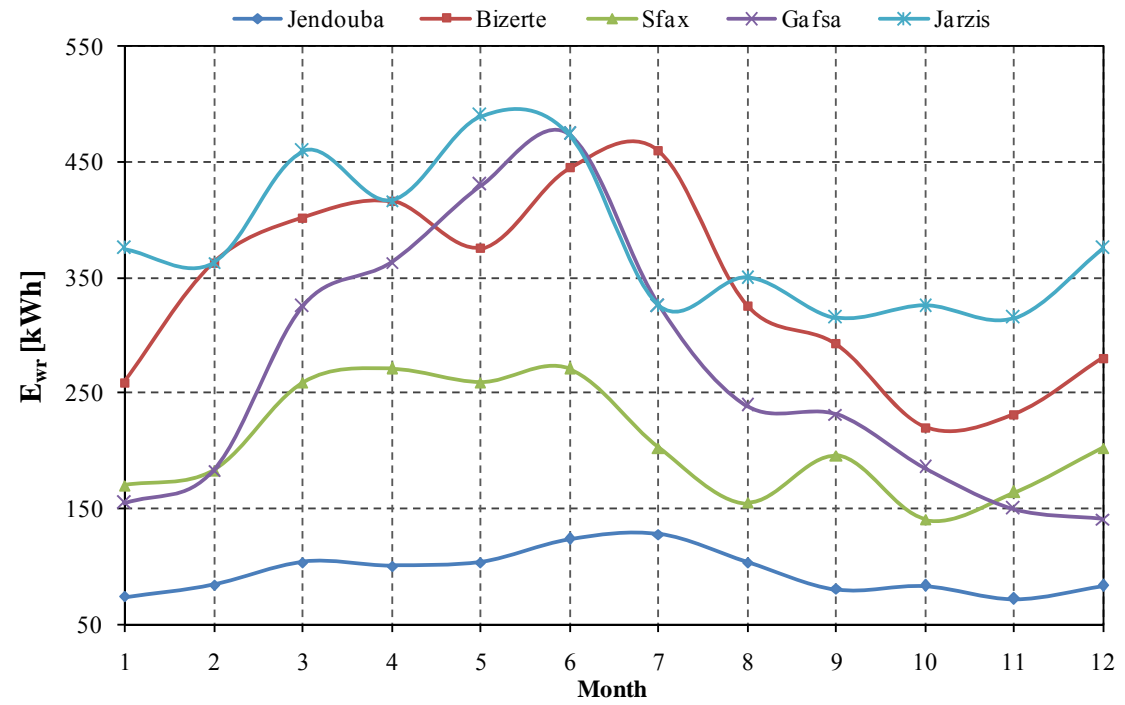

c)

Figure 4 (cont'd.). Yearly variation of the wind energy produced by wind turbines in the different sites b) Type 2 and c) Type 3

\section{Conclusion}

In this study, determination of the wind characteristics and wind power potential in Tunisia is presented using Weibull functions and Betz Theory for five different sites. The following conclusions can be drawn from the results of the present study.

- The maximum average power density occurred as $63.591 \mathrm{~W} / \mathrm{m}^{2}$ in June in Gafsa and in May and June in Jarzis whereas the minimum average value is obtained in Jendouba as $6.521 \mathrm{~W} / \mathrm{m}^{2}$ in October.

- We note that the average wind speed varies from a site to another: Jarzis presents the steadiest and biggest wind energy potential.

- We could reach, in May in Jarzis, $490 \mathrm{kWh}$ as wind energy produced by a small wind turbine that its nominal power doesn't pass $5 \mathrm{~kW}$.

- Jarzis presents the better wind potential. Therefore, it is the most favorable site for the wind installations in the five studied sites.

We could have determined a method that can extract the wind potential characteristics for the different sites and we validated him for the Tunisian sites. After this determination of the wind energy potential, it is necessary to find the best methods of exploitation of this energy. Therefore it is necessary to study the different components of the wind energy conversion system. In this setting, an optimal sizing tool will be presented in our future research works. 


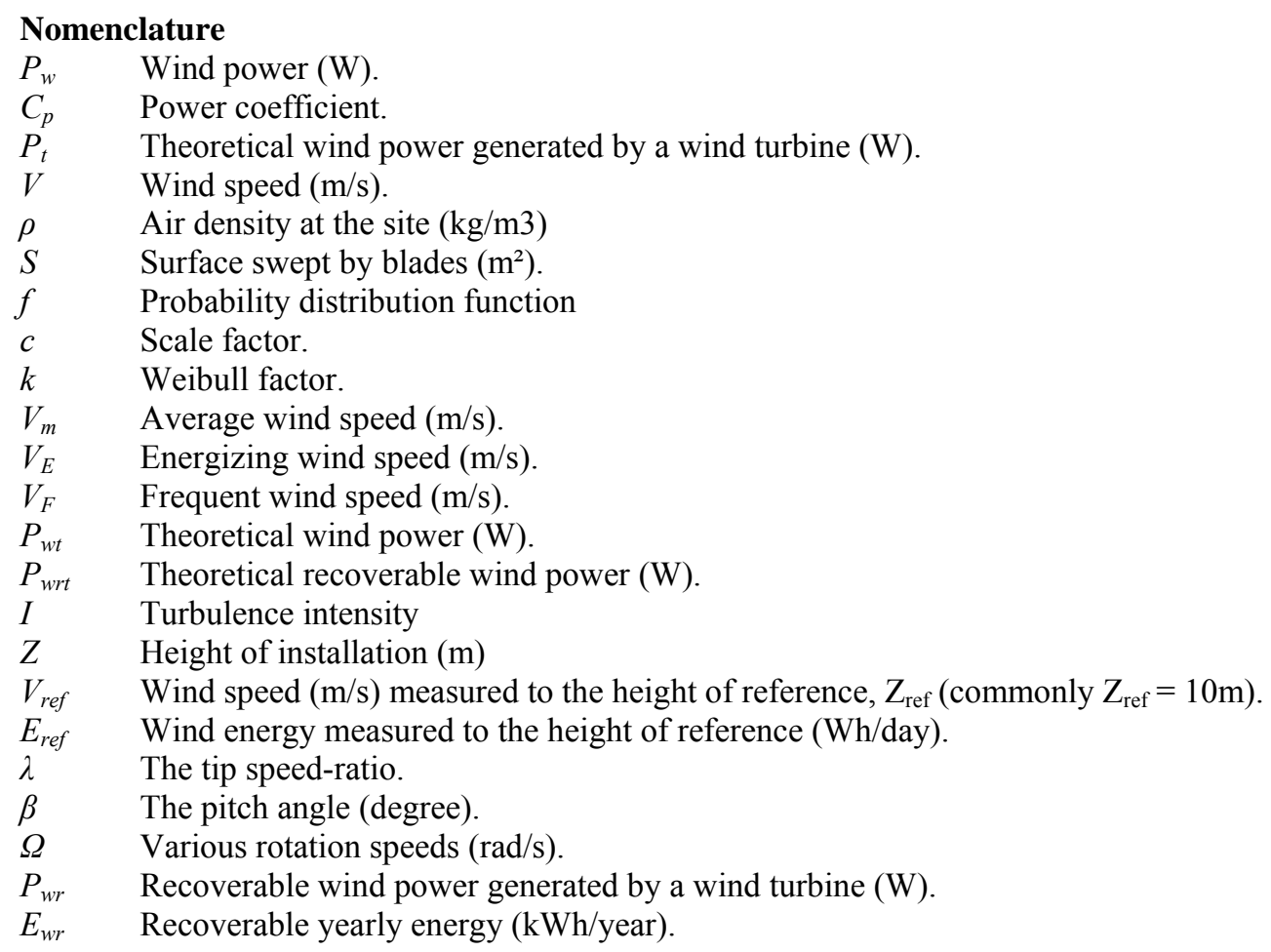

\section{References}

Fyrippis I, Axaopoulos PJ, Panayiotou G, 2010. Wind energy potential assessment in Naxos Island, Greece, Applied Energy, Vol.87, pp. 577-86.

F. Ben Amar, M. Elamouri, R. Dhifaoui, 2008. Energy assessment of the first wind farm section of Sidi Daoud, Tunisia, Renewable Energy, Vol.33, pp. 2311-2321.

Gokcek M, Bayulken A, Bekdemir S, 2007. Investigation of wind characteristics and wind energy potential in Kirklareli, Turkey, Renewable Energy, Vol.32, pp. 1739-52.

J. G. Slootweg et al. 2003. General Model for Representing Variable Speed Wind Turbines in Power System Dynamics Simulations. IEEE Transactions on power systems, Vol.18. No.1, pp.144-51.

Jemaa Brahmi. Lotfi Krichen. Abderrazak Ouali, 2009. A comparative study between three sensorless control strategies for PMSG in wind energy conversion system, Applied Energy, Vol.86, 1565-73.

M. Elamouri, F. Ben Amar, 2008. Wind energy potential in Tunisia, Renewable Energy, Vol.33, pp. 758-768.

M. Elamouri, F. Ben Amar, A. Trabelsi, 2011. Vertical characterization of the wind mode and its effect on the wind farm profitability of Sidi Daoud-Tunisia, Energy Conversion and Management, Vol.52, pp. 1539-1549.

Seyit Ahmet Akdag, Onder Guler, 2010. Evaluation of wind energy investment interest and electricity generation cost analysis for Turkey, Applied Energy, Vol.87, pp. 2574-2580.

Ucar A, Balo F, 2009. Evaluation of wind energy potential and electricity generation at six locations in Turkey, Applied Energy, Vol.86, pp. 1864-72.

RETScreen International, www. retscreen.net [Accessed 15.08.2010].

\section{Biographical notes}

W. Zghal pursues these doctoral studies in Mechanical Genius. He received his master degree from the National Engineering School of Sfax Tunisia in Mechanical and Engineering option new and renewable energies and engineering degree in Electromechanical from the National Engineering School of Sfax Tunisia in the year 2008 and 2007 respectively. His area of interest is Renewable Energy and essentially the wind energy and the solar energy. He has published 3 research papers in different international journals and conferences. Mr. Zghal is currently a researcher in the Laboratory of Electromechanical Systems in the National Engineering School of Sfax, Tunisia.

Dr. G. Kantchev is currently a Conference Professor at the Department of Electromechanical Engineering in the National Engineering School of Sfax, Tunisia. He has published / presented many research papers in reputed international and national journals and conferences. Mr. Kantchev has many patents of invention in different domains. He has written few books related to his research work. He is member in the Laboratory of Electromechanical Systems in the National Engineering School of Sfax, Tunisia. 
Dr. H. Kchaou received his Master degree in Mechanical engineering from the National Engineering School of Tunis in1988 and a PhD in Applied Mechanics from the National Engineering School of Sfax in 1996, Tunisia. He is interested in the field of numerical analysis of mechanical problem, Computational Fluid Dynamics "CFD" and renewable energy. He is author of different articles published in different international journals and conferences. Currently, Mr. Kchaou is Associate Professor of Mechanical engineering at Preparatory School Institute of Engineering Studies of Sfax, Tunisia. He is also member in the Laboratory of Electromechanical Systems in the National Engineering School of Sfax, Tunisia.

Received January 2011

Accepted March 2011

Final acceptance in revised form May 2011 